\title{
Blue cone monochromatism
}

INSERM

\section{Source}

INSERM. (1999). Orphanet: an online rare disease and orphan drug data base. Blue cone monochromatism. ORPHA:16

Blue cone monochromatism (BCM) is a recessive $\mathrm{X}$-linked disease characterized by severely impaired color discrimination, low visual acuity, nystagmus, and photophobia, due to dysfunction of the red $(\mathrm{L})$ and green $(\mathrm{M})$ cone photoreceptors. BCM is as an incomplete form of achromatopsia (see this term). 